\title{
Anti-Caries Effect of Resin-Modified Glass Ionomer Cements as Orthodontic Adhesive Material through Scanning Electron Microscope Examination(In Vitro)
}

\author{
Teguh Aryo Nugroho \\ Master Degree \\ Faculty of Dentistry, Universitas Sumatera Utara \\ Medan, Indonesia \\ tanyateguharyo@gmail.com
}

\author{
Sondang Pintauli \\ Department of Dental Public Health \\ Faculty of Dentistry, Universitas Sumatera Utara \\ Medan, Indonesia
}

\author{
Amalia Oeripto \\ Department of Orthodontic \\ Faculty of Dentistry, Universitas Sumatera Utara \\ Medan, Indonesia
}

\begin{abstract}
One of the major problems of fixed orthodontic treatment is controlling the enamel demineralization that occurs around the bracket. RMGIC is a modified composite resin with anti caries-effect caused by fluoride release. This study aimed to determine the effect of anti caries RMGIC as an orthodontic adhesive material through microscopic examination with SEM. Thirty maxillary first premolars were divided into two groups. One group was bracket-bonded with composite resin material and others with RMGIC. Every group was divided into 3 sub groups, each sub group was soaked in artificial saliva with a pH of 4.5 at $37^{\circ} \mathrm{C}$ for 7,10 and 14 days consecutively. The bracket is de-bonded and the entire samples were then checked using SEM to find out the diameter of the carious lesion. The results showed that the mean diameter of the carious lesion in the sample using the composite resin adhesive material after soaking of 7 days was $10,77 \mu \mathrm{m} \pm 1,00$, after 10 days was 19,08 $\mu \mathrm{m} \pm 7,31$, and after 14 days was $52,50 \mu \mathrm{m} \pm 10,69$. The mean diameter of the caries lesion in the sample using RMGIC adhesive material after soaking of 7 days was 3,52 $\mu \mathrm{m} \pm 1,31$, after 10 days was $7,84 \mu \mathrm{m} \pm 1,66$, and after 14 days was $30,04 \mu \mathrm{m} \pm 4,77$. Samples using RMGIC adhesive materials resulted in smaller mean carious lesion diameter than samples with composite resin material after soaking of 7, 10 and 14 days $(p<0.05)$. Through SEM examination, it is proven that RMGIC has better anti-caries effect compared to composite resin adhesive material.
\end{abstract}

Keywords-resin modified glass ionomer cements, composite resin, fluoride, caries, scanning electron microscope

\section{INTRODUCTION}

One of the main problems of fixed orthodontic treatment is controlling the enamel demineralization around the bracket. Based on research conducted by Richter in 2009, the prevalence of early caries with white spot lesions in fixed orthodontic patients was 73$95 \%[1]$

The use of fluoride, oral hygiene instruction, and diet control can help prevent demineralization during fixed orthodontic treatment, but this method requires patient's cooperation. Another method is by addition of direct fluoride to the adhesive material used in bracket placement [2].

Many adhesive materials can be used in fixed orthodontic treatment, especially in bonding bracket to the teeth. The favorite adhesive material is composite resin [3]. The orthodontic composite resin is a development of resin used for restorative materials with enhanced properties [4].

The development of material technology has resulted in several modifications of composite resin for orthodontic adhesives. One of the main purposes of modifying orthodontic adhesive materials is to control the occurrence of demineralization around the bracket. This is due to treatment of fixed orthodontic which is often associated with increased risk of caries formation [5].

Resin modified glass ionomer cement (RMGIC) is one of the modification of composite resin combining the strength of composite resin bond strength with the fluoride release effect of glass ionomer cement (GIC) [6]. RMGIC as an orthodontic adhesive material is expected to release fluoride, thereby reducing the risk of enamel demineralization [7].

Uysal in 2009 reported that the use of RMGIC as an adhesive material was able to reduce enamel demineralization on tooth fluorescence examination [8]. However, in the orthodontic study, there has not been a more in-depth study to determine the anti-caries effectiveness of RMGIC as an adhesive material in the treatment of fixed orthodontic. 


\section{MATERIALS AND METHODS}

The samples of this study were 30 maxillary first premolars, extracted for orthodontic treatment. The sample had no caries, no enamel abnormalities, and no bracket placement on enamel surfaces. All samples were place on a PVC cylinder with acrylic self cured approximately $2 \mathrm{~mm}$ below the cement enamel junction.

Each sample was cleaned with pumice and brush, etched using 37\% phosphoric acid, then rinsed with aquadest and dried with three way syringe air spray. Bracket bonding procedure is then performed on tooth surface.

The bracket was bonded with composite resin-based adhesives on 15 samples, and with RMGIC-based adhesives on 15 samples. The bracket is held with a bracket tweezers, placed $4 \mathrm{~mm}$ away from the cusps of the premolars along the axis of the tooth, measured using an orthodontic gauge, pressed toward the tooth, and then light cured on each side.

Sample was soaked in artificial saliva with $\mathrm{pH}$ of 4.5 in incubators for 7, 10 and 14 days, each consisted of 5 samples. After soaking, bracket were de-bonded with debonding pliers. Specimens were then prepared to show the diameter of the carious lesion on the cervical portion using SEM with 1000X magnification.

\section{RESULTS}

The existing data were normally distributed to determine difference in the diameter of caries lesion in each group with paired t-test. After soaking of 7 days, the mean diameter of the RMGIC group caries lesion was $3.52 \mu \mathrm{m} \pm 1.31$, smaller than composite resin group of $10.77 \mu \mathrm{m} \pm 1.00$. The results showed significant differences between the composite resin group and RMGIC $(\mathrm{p}<0.05)$ (Table I). This shows that RMGIC as orthodontic adhesive material has anti-caries effect.

TABLE I. THE DIFFERENCE IN DIAMETER OF CARIOUS LESIONS BETWEEN THE COMPOSITE RESIN GROUP AND THE RMGIC GROUP AFTER SOAKING OF 7 DAYS

\begin{tabular}{|l|c|cc|}
\hline \multicolumn{1}{|c|}{ Group } & $\overline{\mathbf{x}} \pm$ SD & $\boldsymbol{p}$ \\
\hline CR & $10,77 \pm 1,00$ & \multirow{2}{*}{0,000} & \\
\hline RMGIC & $3,52 \pm 1,31$ & & \\
\hline
\end{tabular}

After soaking of 10 days, the mean diameter of caries lesions in the RMGIC group was $7.84 \pm 1.66 \mu \mathrm{m}$, smaller than in the composite resin group which was $19.08 \pm 7.31 \mu \mathrm{m}$. The results showed significant differences between the composite resin group and RMGIC group $(p<0.05)$ (Table II). This confirms the anti-caries effect of RMGIC as orthodontic adhesive material.

TABLE II. THE DIFFERENCE IN DIAMETER OF CARIOUS LESIONS BETWEEN THE COMPOSITE RESIN GROUP AND THE RMGIC AFTER SOAKING OF 10 DAYS

\begin{tabular}{|c|c|c|}
\hline Group & $\overline{\mathbf{x}} \pm \mathbf{S D}$ & $p$ \\
\hline CR & $19,08 \pm 7,31$ & \multirow{2}{*}{0,010} \\
\hline RMGIC & $7,84 \pm 1,66$ & \\
\hline
\end{tabular}

After soaking of 14 days, the average diameter of the caries lesions in RMGIC group was $30.04 \pm 4.77$ $\mu \mathrm{m}$, smaller than in the composite resin group which was $52.50 \pm 10.69 \mu \mathrm{m}$. The results showed significant differences between the composite resin group and RMGIC ( $\mathrm{p}<0.05)$ (Table III). This shows that RMGIC as orthodontic adhesive materials has anti-caries effect.

TABLE III. THE DIFFERENCE IN DIAMETER OF CARIOUS LESIONS BETWEEN THE COMPOSITE RESIN GROUP AND THE RMGIC GROUP AFTER SOAKING OF 14 DAYS

\begin{tabular}{|l|c|cc|}
\hline \multicolumn{1}{|c|}{ Group } & $\overline{\mathbf{x}} \pm$ SD & $\boldsymbol{p}$ \\
\hline CR & $52,50 \pm 10,69$ & 0,000 & \\
\hline RMGIC & $30,04 \pm 4,77$ & & $p<0.05$ \\
\hline
\end{tabular}

\section{DISCUSSION}

The most commonly used orthodontic adhesive material is a composite resin-based material without any anti-caries effect. During fixed orthodontic treatment the adhesive material will interact with saliva. Saliva component especially $\mathrm{pH}$ will affect tooth condition, where decrease of saliva $\mathrm{pH}$ will cause demineralization process in tooth.

In this study, there was an average difference in the size of the caries lesion after samples were soaked for 7 , 10 and 14 days at $\mathrm{pH} 4.5$ (cariogenic). Samples with RMGIC adhesive material, after soaking of 7 days, had the lowest mean carious lesion diameter, i.e. $3.52 \mu \mathrm{m} \pm$ 1.31. Sample with the largest mean diameter carious lesion was found in the sample with the composite resin material after soaking of 14 days, i.e. $30.04 \mu \mathrm{m} \pm 4.77$. The size of the lesion is still not visually visible, which can be visually detected when reaching the size of 500 $\mu \mathrm{m}[9]$.

The results are consistent with the study results of Shetty (2015) and Shetty (2015), which stated that RMGIC adhesive materials have anti-caries effects when compared with composite resin adhesive materials. In this study, it is found that the longer the sample has been soaked in artificial saliva $\mathrm{pH} 4.5$, the larger the diameter of the caries lesions will be observed in the SEM examination. This is presumably due to the continuous process of sample demineralization $[10,11]$.

In samples with RMGIC material, fluoride release from RMGIC is insufficient to prevent the demineralization process when the tooth is exposed to long-term cariogenic $\mathrm{pH}$. According to Dos Santos in 2013, the fluoride release process of RMGIC is an acidbase reaction when mixing powder and liquid. Resin Modified Glass Ionomer Cements will maintain fluoride release during the first month before gradually decreasing, so remineralization is needed for RMGIC fluoride uptake process [12].

Resin Modified Glass Ionomer Cements as an orthodontic adhesive material has a fluoride release effect and can help prevent demineralization of the teeth. Orthodontic treatment is a long-term treatment, to determine the effect of fluoride release from RMGIC on caries prevention during orthodontic treatment, further 
research is needed. Based on the results of research and discussion, it can be concluded that SEM examination shows RMGIC as orthodontic adhesive material with anti-caries effect.

\section{REFERENCES}

[1] A.E. Richter, A.O. Arruda, M.C. Peters, W. Sohn, "Incidence of caries lesions for patients treated with comprehensive orthodontics," J Dent Res 88(Spec Iss A): Abstract. Miami Meeting. 2009

[2] C.B. Arcís, et al., "Orthodontic treatment need: An epidemiological approach. Orthodontic-Basic Aspects and Clinical Considerations," Stomatology Department, University of Valencia Spain, 2012.

[3] R.V. Vilar, N.F. Souza, J.P. Cal-Neto, M. Galvao, F.H. Sampaio, A.M. Mendes, "Shear bond strength of brackets bonded with two light curing orthodontic adhesives," J. Adhes. Dent., vol. 11, pp. 259-262, 2009.

[4] S. Sapir, "Considerations in orthodontic bracket adhesion to hypomineralized enamel, Principles in contemporary orthodontics,” Dr. Silvano Naretto (Ed.), InTech, 978-953-307687-4, 2011.

[5] F. Bourzgui, M. Sebbar, M. Hamza, "Orthodontics and caries, principles in contemporary orthodontics," Dr. Silvano Naretto (Ed.), InTech, 978-953-307-687-4, 2011.
[6] M.L. Brown, H.B. Davis, E. Tufekci, J.J. Crowe, D.A. Covelle, J.A. Mitchellf, "Ion release from a novel orthodontic resin bonding agent for the reduction and/or prevention of white spot lesions an in vitro study," Angle Orthod., vol. 81, pp. 1014 1020, 2011.

[7] V. Cacciafesta, M.F. Sfondrini, P. Taglian, C. Klersy, "In-vitro fluoride release rates from 9 orthodontic bonding adhesives," Am. J. Orthod. Dentofacial Orthop., vol.132, pp. 656-662, 2007.

[8] T. Uysal, M. Amasyali, A.E. Koyuturk, D. Sagdic, "Efficiency of amorphous calcium phosphate-containing orthodontic composite and resin modified glass ionomer on demineralization evaluated by a new laser fluorescence device," Eur. J. Dent., vol. 3, pp. 127-134, 2009

[9] S. Abrams, "Do we really need caries detection devices?" Dental Teamwork, vol. 7, pp. 46-50, 2014.

[10] S. Shetty, S. Hegde, Kalavani, M.V. Ashith, R. Siddharth, "Comparative evaluation of enamel using conventional light cure composite resin and RMGIC an invivo study," I. J. Pre. Clin. Dent. Res., 2, vol. 3, pp. 15-22, 2015.

[11] V. Shetty, K. Akhsaya, K. Shetty, N. Shetty, "Evaluation and comparison of enamel demineraization around orthodontic brackets using two different adhesive material," I. J. Pre. Clin. Dent Res., 2, vol. 3, pp. 28-33, 2015.

[12] R.L. Dos Santos, M.M. Pithon, A.B.N Fernandes, F.G. Carvalho, A.L. Cavalcanti, D.S. Vaitsman, "Fluoride release/uptake from different orthodontic adhesive: A 30 month longitudinal study," Brazilian Dental Journal, vol.24, pp. 410$414,2013$. 